Wilfrid Laurier University

Scholars Commons @ Laurier

Fall 1995

\title{
Changing Relationships Between Self-Help Groups and Mental Health Professionals: Shifting Ideology and Power
}

Vic Constantino

Wilfrid Laurier University

Geoffrey Nelson

Wilfrid Laurier University, gnelson@wlu.ca

Follow this and additional works at: https://scholars.wlu.ca/psyc_faculty

Part of the Psychiatry and Psychology Commons

\section{Recommended Citation}

Constantino, Vic and Nelson, Geoffrey, "Changing Relationships Between Self-Help Groups and Mental Health Professionals: Shifting Ideology and Power" (1995). Psychology Faculty Publications. 28. https://scholars.wlu.ca/psyc_faculty/28 


\title{
CHANGING RELATIONSHIPS BETWEEN SELF-HELP GROUPS AND MENTAL HEALTH
PROFESSIONALS: SHIFTING IDEOLOGY AND POWER
}

VIC CONSTANTINO and GEOFFREY NELSON Wilfid Laurier University

\begin{abstract}
Using qualitative methods, we studied current and desired relationships between members of mental health consumer/survivor and family self-help groups and mental health professionals. Two major themes, professional ideology and practices and power and control, captured both the positive and negative aspects of the relationships the participants had experienced. To move toward more desired relationships, participants suggested education and ongoing interaction between self-helpers and professionals are needed to change professional ideology and practices, while consumer/survivor and family participation and involvement in decision making are required to reduce the power imbalance between self-helpers and professionals. We discuss the implications of the findings for changes in training, practice, and research.
\end{abstract}

Many people who have studied self-help groups (SHGs) have asserted that the culture or ethos of self-help (SH) is very different from that of professional help (PH) (Borkman, 1990; Bryant, 1990; Farquharson, 1990; Katz \& Bender, 1990; Powell, 1990; Rappaport, 1993). PH is based on technical knowledge and emphasizes problem solving: professionals are paid; help flows one-way from the professional to the client; and helping activities are scheduled, organized, and constrained by time. On the other hand. SH is based on experiential knowledge and emphasizes social support; SHG members are not paid; SH involves mutual aid with members both providing and receiving help; and helping activities are more spontaneous, unstructured, and unconstrained by time. Given the growing number of SHGs in North America (Jacobs \& Goodman, 1989), it is important to understand the relationships between SHGs and professionals. The purpose of this research is to describe and analyze current and desired relationships between SHGs and professionals in the mental health field and to examine strategies for changing current relationships to desired relationships. We begin by reviewing the literature pertinent to these research goals.

There have been very few empirical studies of the relationships between SHGs and professionals. While several attitude surveys have found that most professionals hold very positive attitudes towards SHGs (Bryant, 1990; Levy, 1978; Salzer, McFadden, \& Rappaport, in press: Todres, 1982), a few studies have un-

Address correspondenec regarding this article to Vic Constantino, Mutual Life of Canada, 227 King St. South, Waterloo, ON N21 4CS or Geoffrey Nelson. Department of Psychology. Wilfrid Laurier University, Waterloo ON N2L. 3C5. The authors thank Isaac Prilleltensky for his helpful suggestions regarding this paper and Nicole Nelson for her help in drawing the diagram. 
covered professional biases or fears regarding SHGs. In a study of over 800 mental health professionals, Salzer et al. (in press) reported that professionals from both hospitals and community programs always believed PH to be superior to SH. In a qualitative study, Chesler (1990) discovered that professionals questioned the effectiveness of SHGs and felt threatened by anti-professional attitudes, emotional attacks, challenges to professional "authority," and competition with the professional service monopoly by SHGs.

In considering SHG members' views of professionals, it is important to keep two considerations in mind. First, in the mental health field, SHGs have been developed by two different stakeholder groups: (a) people who have experienced mental health problems, who increasingly refer to themselves as "consumers" or "survivors" (Burstow \& Weitz, 1988; Chamberlin, 1978), and (b) parents and family members of people with mental health problems (Pomeroy \& Trainor, 1991). Second, many consumer/survivor and family SHGs were born out of negative experiences with mental health professionals. For example, in Canada, some members of consumer/survivor groups have experienced some professionals as paternalistic and abusive and have an explicit anti-psychiatry orientation (Burstow \& Weitz, 1988; Chamberlin, 1978), Similarly, family members tend to be dissatisfied with professional services for their relatives with severe mental illness (Hanson \& Rapp, 1992). In describing the origins of the family SH movement, Grosser and Vine (1991) stated:

Families were frustrated by a system of mental health care delivery that failed to consider their needs a priority, disappointed by the inadequacy of programs for their discharged relatives, and angered by their negative experiences in working with professionals, clinicians, and public servants (p. 282).

It should be noted that there is great diversity both among SHGs and mental health professionals. For example, some SHGs, like Recovery Inc. (Raiff, 1984), have positive attitudes and working relationships with professionals, and many family SHGs espouse a medical model of mental illness (Pomeroy \& Trainor, 1991). On the other hand, some SHGs in the mental health field do not want a partnership with professionals, but instead prefer to opt for a separatist model (Chamberlin. 1978). In a survey of 104 consumer/survivor SHGs in the U.S., Emerick (1990) found that the majority of groups held attitudes toward mental health professionals that were either negative or neutral. Moreover, separatist SHGs showed the lowest level of interaction with and the highest level of antiprofessional attitudes compared with SHGs that were characterized as either supportive or partnership in orientation. Similarly, in another survey of 425 SHGs in California, Lotery and Jacobs (1994) found that members of psychiatric consumer/survivor SHGs believed professionals were less helpful than did members of other types of SHGs.

Consumer/survivors and family members have reported both positive and negative experiences with professionals (Stewart, Banks, Crossman, \& Poel, 1994). While some have experienced professionals as abusive and controlling (Burstow \& Weitz, 1988: Penfold, 1992), others have found professionals to be supportive and helpful (Stewart et al., 1994). Several writers have suggested supportive roles that professionals can play vis-à-vis SHGs, including: (a) providing referrals to SHGs, (b) providing tangible support, (c) sharing information, (d) 
offering consultation, (e) helping to start SHGs, and (f) doing participatory action research with SHGs (e.g., Farquharson, 1990; Gotlieb, 1982; Katz \& Bender. 1990). Professionals have worked in these roles with SHGs in the formation and operation of self-help clearinghouses (Madara, 1990). In these instances, professionals have operated from an empowerment framework, rather than the traditional expert framework, in which professionals paternalistically assume they know best what their clients need. The essence of an empowerment approach is that people who have been marginalized gain more control over their lives through active participation in the community (Lord \& Hutchison, 1993). Professionals who work from an empowerment approach are respectful and supportive of SHGs and share decision-making power with and provide resources to SHGs.

To move toward more desired relationships, several strategies for change have been suggested in the literature. First, education of professionals about SHGs is necessary for changes in professional role from "expert-technician" to "resourcecollaborator" (e.g., Farquharson, 1990; Katz \& Bender, 1990; Reiff, 1974; Tyler, Pargament, \& Gatz, 1983). SHG members have used the phrase, "keeping professionals on tap, not on top." to get at this shift in professional roles. Second, consumer/survivor and family participation in mental health policy, planning, and service-delivery is needed to reduce the power imbalance between professionals and service users (Church \& Reville, 1989). For example, family and consumer/ survivor SHGs have been recognized as important sources of informal aid in the framework for support developed by the Canadian Mental Health Association (CMHA) (Trainor \& Church, 1984; Trainor et al., 1992). Finally, consumer/ survivor and family SHGs must have an adequate resource base themselves and a secure sense of identity before they can participate in "partnerships" with mental health professionals, as partnership implies equality (Labonté, 1993).

There is one recent study whose methods and findings are very relevant for this investigation and merit special attention. Stewart et al. (1994) used qualitative methods to study the relationships between 48 health professionals and 50 SHG members with a variety of health and lifestyle concerns in Nova Scotia. A main focus of the research was on developing "partnerships" between these two groups. Reciprocity, helpfulness, complementarity, collaboration, understanding, and clear roles were positive aspects of the relationships between these two groups, while competition, territorialism, authoritarianism, dominance, non-supportiveness, and judgement were some of the negative qualities of the relationships. Some of the characteristics of desired relationships between SHGs and professionals included understanding, reciprocity, trust, and decreased professional control, while barriers to these relationships consisted of funding mechanisms, ideological conflicts, control/monopoly of services, and poor communication. Some of the strategies that SHG members and professionals suggested for overcoming these barriers to achieve more desired relationships were education of professionals, communication and trust-building, role and goal clarification, and creating a self-help clearinghouse,

In the present study, we examine the relationships between SHGs and professionals in the mental health field. In this field, the attitudes of consumer/survivor SHG members toward professionals tend to be more negative than with other types of SHGs (Emerick, 1990; Lotery \& Jacobs, 1994); many family members also tend 
to have negative attitudes toward professionals (Hanson \& Rapp, 1992); and there are glaring differences in power and social class between psychiatric consumer/ survivors and professionals (Church, 1992, 1994). Therefore, our analysis of the relationships between SHGs and mental health professionals focuses on issues of power. To study these relationships, we used a participatory action research approach, which is described more fully in the next section. Consumer/survivors, family members, and professionals, the key stakeholders in the project, wanted to develop more supportive relationships. To achieve this broad goal, they decided to address the following questions in this research:

1. What are the experiences of SHG members (both consumer/survivors and family members) and mental health professionals (both hospital and community-based) with one another?

2. What are the desired relationships between SHG members and mental health professionals?

3. What strategies do SHG members and mental health professionals suggest for moving from current to desired relationships?

\section{METHOD}

\section{Context}

This study has its origins in the work of the two authors who, in their capacity as board members of a community mental health agency, helped the community to develop and operationalize a self-help clearinghouse. Moreover, the study was conducted during 1993 when mental health agencies in the community were beginning to place increased emphasis on consumer/survivor and family participation in the governance and operation of their programs. The setting for the research is a medium-sized urban area with one general hospital which provides inpatient and out-patient treatment for people with mental health problems and two community mental health agencies, one of which provides supportive housing while the other operates community support programs and hosts several SHGs.

\section{Research Process, Methods, and Sample}

A participatory action research approach was used (Chesler, 1991; Lavoie, 1984). The major stakeholders who were invited to participate in the project were two consumer/survivor SHGs, one SHG for family members, the two community mental health agencies, and the hospital's mental health services. These stakeholders were selected as they constitute the main resource groups in CMHA's framework for support (Trainor \& Church, 1984: Trainor et al., 1992). Representatives from these groups, including two members of consumer/survivor SHGs, one member of a family SHG, and two mental health professionals, met once a month over a period of nine months with the first author to: formulate the purpose of the study and research questions, decide on research methods, invite members of their organizations to participate in the study, interpret the findings, and suggest how the findings could be used to promote change.

Interview guides were developed for professionals and self-helpers. The questions were open-ended and focussed on experiences and relationships between SHGs and professionals, desired relationships between these two groups, and 
barriers to and strategies for improving relationships. Sample questions for professionals are: "What kind of relationship do self-helpers and professionals have in your setting?", "What kind of relationship should professionals and self-helpers have?". "What are the barriers between professionals and self-helpers?" Sample questions for self-helpers are: "What kind of relationship do self-helpers and professionals have in your experience?". "What kind of relationship should selfhelpers and professionals have?", and "What are the barriers between self-help groups and professionals?"

Thus, a qualitative approach to the research was used. Focus group interviews were conducted with the staff of two community mental health agencies and the hospital's mental health services and with the members of two consumer/survivor SHGs and one family SHG. All participants were informed of the purpose of the research and all gave their written consent to participate in the interviews and to bave the interviews tape recorded. There were six hospital-based and $12 \mathrm{com}$ munity-based professionals ( 16 women and two men), including social workers, psychiatric nurses, and marriage and family counsellor/therapists, and five family SHG members and 11 consumer/survivor SHG members (eight women and eight men), for a total of 34 participants.

\section{Data Analysis}

All the interviews were transcribed, and the first author used open coding (Strauss \& Corbin, 1990) to categorize phrases, sentences, and paragraphs. Responses to each interview question were coded separately. The codes were revised, refined, and compared with those obtained by Stewart et al. (1994). We also compared the codes obtained for the SHG and professional data. A second level of analysis involved what has been called axial coding (Strauss \& Corbin, 1990). The two authors developed overarching themes that connected the categories to develop a grounded theory of the relationships between SHGs and mental health professionals. This process involves a higher-order analysis of the data from these specific circumstances, whereby we tentatively suggest postulates that advance our understanding of the particular findings (see Peirson \& Prilleltensky, 1994, for further explanation of grounded theory).

We employed several methods to ensure the trustworthiness of the data (Lincoln \& Guba, 1985). The first author was immersed in the settings. He attended several meetings of SHGs, worked with them in the creation of a self-help clearinghouse, and became familiar with the staff of one community mental health agency in his role as board member. Finally, the advisory group for this project helped to ensure that the realities of the different stakeholder groups would be reflected in the research. This involvement with the participants and the settings helped to establish the credibility of the findings. To aid others in determining the transferability of the findings, we have described the research context in some detail. Moreover, the comparison of these findings with those of Stewart et al, (1994), who used similar methods and participants, demonstrates the transferability of the findings. 


\section{RESULTS}

In reporting results, we present the major findings across the stakeholder groups. However, we do make note of any variations in the responses by different groups, when there were such differences. The results are presented in terms of current relationships, desired relationships, and strategies for change, as depicted in Figure 1. Within each of these three areas, there are two major themes that emerged from the axial coding: (a) professional ideology and practices, and (b) power and control. These two themes captured and connected many of the categories from the process of open coding. The schematic in Figure 1 represents our grounded theory of the changing relationships between SHGs and professionals. Specifically, our theory emphasizes the shifting nature of ideology and power in these relationships.

\section{Current Relationships Between Self-helpers and Professionals}

Professional ideology and practices. The current relationships between selfhelpers and professionals is heavily influenced by the ideology, attitudes, and practices that are emphasized in the socialization and training of professionals.

\section{FIGURE 1}

Grounded Theory of the Changing Relationships Between Self-Help Groups and Mental Health Professionals

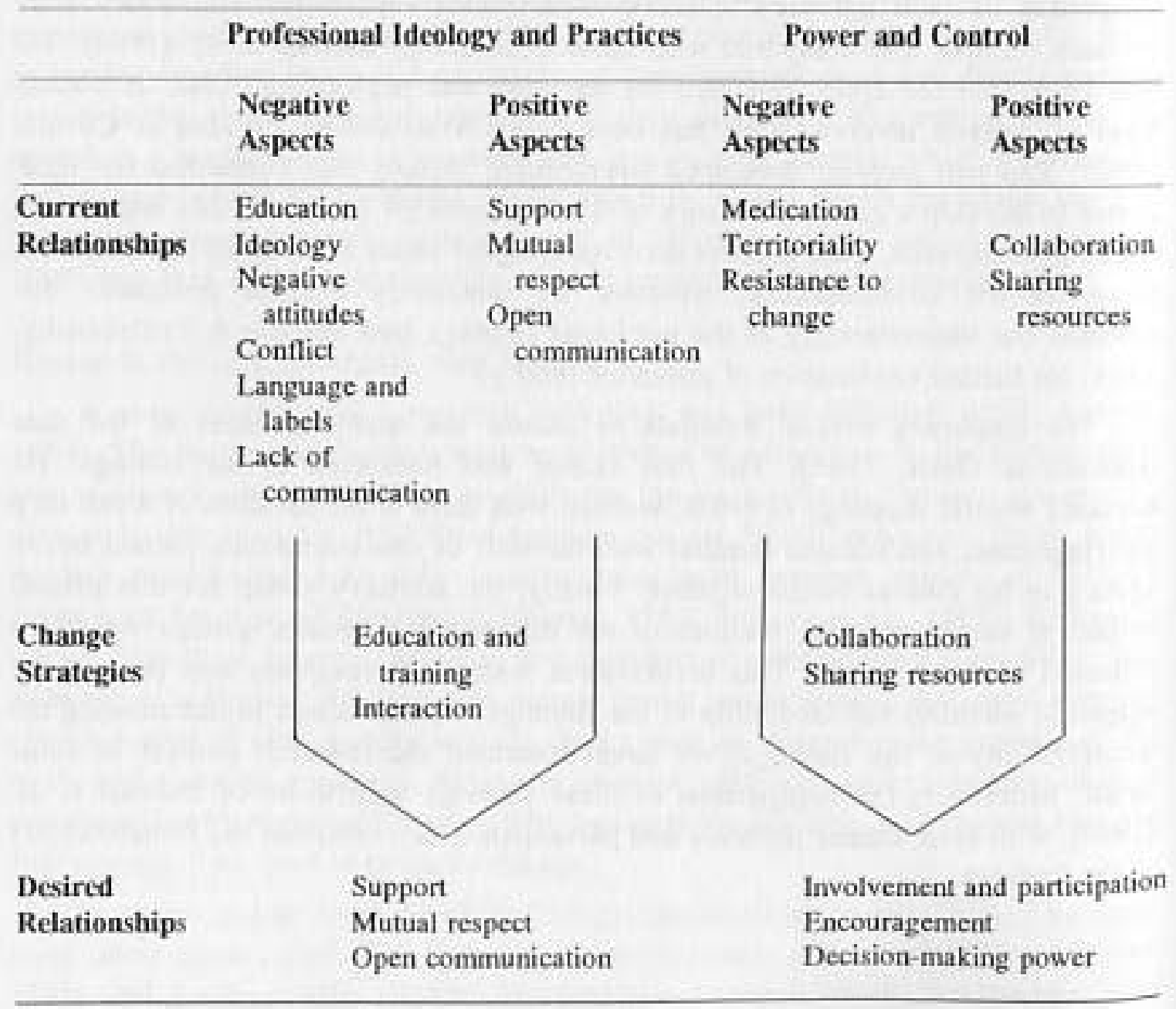


Both self-helpers and professionals noted the importance of education and asserted that professionals do not receive training about SHGs and they do not have the opportunities to learn about self-helpers' personal experiences in their training. Furthermore, many professionals are not aware of SHGs available in the community that could be helpful to consumers and family members. Professionals argued this lack of knowledge about SHGs is partly because of their busy schedules.

Both SHG members and professionals said the education of professionals promotes an ideology which emphasizes distance, expertise, and clinical and textbook knowledge, whereas the ideology of SHGs is based on experiential knowledge, intuition, and subjectivity. One consumer said:

I think that perhaps they look at things too clinical, too much textbook. ... I also feel that it is not necessary to delve into childhood. ... You want to live now, like how do 1 get out of this now, and tell me the coping techniques, never mind talking about things that happened 30 years ago...... It's not the magic bullet either.

These ideological differences cause conflict to arise. Similarly, negative attitudes on the part of consumer/survivors and family members toward professionals and professionals toward SHGs contribute to this conflict. Professionals admitted feeling threatened by SHGs that have anti-psychiatry and anti-professional attitudes. At the same time, self-helpers said some professionals look down on SHGs and do not believe self-help works. Some consumer/survivors stated that professionals ridiculed them when they wanted to join SHGs.

When I went to see my doctor and informed him that I was going to the support group, he kind of just snickered a bil. So I don't really think they take it seriously,

Furthermore, these conflicts, negative attitudes, and differences in ideology manifest themselves in various practices that are problematic. For example, professionals said the language and labels they use can be stigmatizing and demoralizing to their clients and can reinforce "us" and "them" divisions. A lack of communication between self-helpers and professionals is also problematic. Self-helpers said professionals do not adequately communicate information regarding diagnoses, medication, or other treatments. Again professionals cited limited time and busy schedules as contributing to lack of communication.

In spite of these divisions and problems, both SHG members and professionals commented on positive aspects of their interactions with one another. SHG members appreciate the support they receive from professionals. For instance, selfhelpers said professionals are helpful when they refer people to SHGs, when they share their expertise with SHGs, and when they show compassion and understanding. Professionals said it is important to respect SHGs' goals, objectives, and perspectives and to listen to consumer/survivors and family members. Finally, both professionals and self-helpers noted that open communication between the two contributes to healthy relationships.

Power and control. Self-helpers said "professionals like to control," because they possess knowledge, and knowledge is power. When speaking of issues of power and control, self-helpers were referring primarily to hospital-based professionals, particularly psychiatrists. There are many ways that professionats 
exercise power and control. Consumer/survivors mentioned that doctors use medication as a control technique. Some consumer/survivors' experiences with medication were terrifying, while others said they were not informed about the side-effeets of medications and could not truly give their informed consent. Both family members and consumer/survivors commented on this.

Perhaps the worst experience was with one psychiatrist, who very nearly killed our son. He had him on lithium, and it proved toxic. He admitted he'd made a mistake.... My son is still suffering from this.

Ive been locked up in the hospital, if you want to call that a conflict. Six people grabbed me, and ran me into the isolation and stuck a needle in. .... I was immediately put in isolation for a week.

Professionals and self-helpers said some professionals demonstrate territoriality and perceive SHGs to be a threat to their power base and livelihood. Moreover, professionals noted that they show resistance to change to protect their interests.

On the other hand, professionals and SHG members noted that some professionals share power and control. Both noted that some professionals have demonstrated collaboration with SHGs on a variety of planning and service-delivery issues. Sharing resources was another facet of working with SHGs. As one selfhelper said:

They [an agency] have been very helpful, giving and telling us what resources are available, and for meeting what we want to do. That has, 1 think, been quite good.

\section{Desired Relationships Between Self-helpers and Professionals}

Professional ideology and practices. More than anything else, mutual respect topped the agenda for both self-helpers and professionals about the kind of relationship they would like to have. Support from professionals was also very important for SHG members. Likewise, professionals stated they would like to work with SHGs toward the common goal of promoting the well-being of their clients. Finally, open communication between professionals and SHGs is important for building positive relationships. One professional stated: "that seems to be a major thing that comes out, communication, how we can bridge and how we can meet the needs of clients." Similarly, a consumer noted the importance of a "... willingness and readiness to listen and to accept the point of view that doesn't necessarily correspond with the other person's."

Power and control. Both self-helpers and professionals said collaboration between the two was one way of sharing power and control. However, these two groups differed in their perceptions of how equal collaborative relationships, or partnerships, could be. One family self-helper made this statement about partnership and participation:

Parnership will never be equal. . . It's democratic. It's important in relation to self-esteem, if you like. It's even more important for the consumer/survivors because they have been put down so often and they've put themselves down so ofteri. ... I think it's not easy, but I think it's possible, if people are willing to really give it a try.

On the other hand, professionals said equal partnerships between SHGs and professionals are possible. One professional said: 
Partnership should be on an equal basis. And I say the big thing that comes up to me is the equality, that would be equality in roles and participation and responsibility. A partnership to me is that you are playing equal roles.

On the other hand, one professional acknowledged difficulties in partnerships between SHGs and professionals.

I think that when we're talking about partnerships, professionals have to be constantly vigilant, 'cause there is a tendency towards paternalism. When we are in a relationship with self-helpers, we should not only do that on an individual basis, but within our system. We have to be able to provide avenues and ways in which that kind of paternalism can be guarded against. Rather than having an agency where professionals are kind of deciding on what selfhelp needs to be done ... the professionals should become a resource, without necessarily taking over (the SHGs).

Both self-helpers and professionals noted the necessity of sharing resources. Self-helpers spoke of how professionals could share their skills and offer assistance to SHGs. Professionals noted that agencies could share their libraries, research, and staff with SHGs.

\section{Strategies for Change}

Changes in professional ideology and practices. To move from current to desired relationships between SHGs and professionals, education and training were seen as indispensable. A self-helper commented that "professionals have a lot to learn from SHGs." Similarly, professionals commented on the need for "better education of psychiatry and doctors about self-help." Both self-helpers and professionals said training about self-help should be incorporated into the curricula of graduate training programs in the mental health professions. As well, participants spoke of the need for professionals to stay abreast of new developments in self-help on an ongoing basis. Central to the notion of education was the belief that there needs to be more interaction between members of SHGs and professionals. In this way, the two groups can learn more about one another and come to a better understanding of each others' experiences and viewpoints. One self-helper stated: "I hope that it [this study] leads to more interaction between professional organizations and SHGs."

At the same time, both professionals and self-helpers stated that education and training is also important for self-helpers, as they can "learn something from them [professionals]," Moreover, one professional commented that self-helpers need an orientation and training about how to participate on agency committees and boards.

Changes in power and control. Several strategies were mentioned for reducing the power imbalance between self-helpers and professionals. First, increased involvement and participation of consumer/survivors and family members in agency committees and boards was one strategy. As one professional said:

That is the goal for the hospital to have more strategic goals and priority towards having patients involved in more committees and staff, for example, some kind of advisory committee.

Moreover, both self-helpers and professionals expressed that professionals must provide encouragement to promote more involvement and participation of family members and consumer/survivors. Professionals recognized that their agencies and 
staff must change themselves to create meaningful opportunities for consumer and family participation.

Both SHG members and professionals also noted that consumer and family participation must include decision-making power regarding planning, policy, and service-delivery issues. One self-helper said:

I really think that you need the self-helpers and the clients on some of these decision-making processes. I think they are moving in that direction, which I think is good, although my experience has been that the professionals still dominate it.

A professional made the following comment about decision making.

I think the overall (agency) has certainly moved in that direction.... We're aiming towards it. So in some areas, people don't really make decisions, but I would say that we're trying to hand over more responsibility, and let people know that they do have the abilities to take responsibility and make decisions.

\section{Developments Since Completion of the Study}

In the year and a half since the study was completed, it is our impression that relationships between consumer/survivor and family SHGs and mental health organizations have grown and improved. For example, an open forum, which was organized by several of the stakeholders in this study and to which consumer/ survivors, family members, and professionals were invited, was held at the time this paper was being revised. To quote from the flyer advertising this event:

In December, a number of organizations from service providers, consumer/ survivor groups, and family support organizations (sic) met to look at how they could begin to establish a common understanding of issues related to mental health services and of principles which should underline the establishment of priorities for change. From the day, the participants created some directions, one of which was to establish a town meeting, or a series of town meetings for the mental health community in which this document and potential future actions would be addressed.

Moreover, based on our observations and conversations with stakeholders from the study, it appears that consumer/survivors and family members are well represented on the boards and/or committees of the three mental health organizations that participated in this study.

The reader should bear two caveats in mind regarding these developments. First, what we are reporting here is based on our impressions of what has happened, rather than a systematic study of such changes. Second, it would be naive for us to conclude that any changes in the relationships between SHGs and professionals resulted directly from this study. During the period of time in which the study was conducted, there were many other forces of change that were leading to more consumer/survivor and family participation in the mental bealth system. These forces were operating at both the social policy level in the provincial health ministry and in the organizations that were involved.

\section{DISCUSSION}

Professional ideology and practices was one of the central postulates that emerged from the data. Both family and consumer/survivor SHG members and pro- 
fessionals identified education, ideology. language and labels, negative attitudes, and lack of communication as aspects of professional ideology and practice that lead to conflict in the relationship between self-helpers and professionals. The different world views of SHG members and professionals (Rappaport, 1993) have their roots in very different social contexts and life experiences. The orientation of most professional training programs socializes professionals in an ideology that locates problems within individuals, not in their social environments, and that views PH as indispensable for helping "clients." Moreover, professional practices that reinforce the differences between "us" and "them," such as diagnosis and labelling, alienate professionals from consumers and family members (Levine. 1982). On the other hand, many SHGs have grown out of a context of dissatisfaction and anger with $\mathrm{PH}$ and have strived to develop supportive and egalitarian relationships within their groups (Chamberlin, 1978). Furthermore, professionals are highly valued in society and are well-paid and well-recognized for their work, whereas psychiatric consumer/survivors and family members have been blamed for their problems, isolated, and stigmatized by society (Nelson \& Walsh-Bowers, 1994). Thus, the different world views of and conflicts between SHG members and professionals are deeply rooted in a social context.

We found that self-helpers and professionals value respect, support, and open communication. These are the positive aspects of professional ideology and practice, and it is these interpersonal and human qualities of professionals, more than technical skills. that SHG members find to be most desirable. These findings regarding both problematic and positive aspects of the relationships between selfhelpers and professionals are very similar to those obtained by Stewart et al. (1994). While surveys have found that professionals hold mostly positive attitudes toward SHGs (e.g., Levy, 1978; Todres, 1982), the findings of this study and that of Stewart et al. (1994) shed more light on the relationships between self-helpers and professionals in that the focus was on people's actual experiences of relationships, not on attitudes. Using qualitative methods allowed us to go beneath the surface of espoused positive attitudes of professionals and uncover fears and conflicts as well as positive experiences between these two groups.

Our findings also underscore power and control as another central theme in the relationships between professionals and SHGs. The control of knowledge and resources (Reiff, 1974) is basic to the privileged status of professionals. Consumer/ survivors and, to a lesser extent, family members noted serious problems with medication. Lack of information about medications and forced treatment were the main issues which illustrated the abuse of power by professionals (Burstow \& Weitz, 1988; Chamberlin, 1978). Like Chesler (1990), we found that challenges to professional authority were sometimes met with resistance to change and territoriality. When there is a large difference in power and control between two groups, such as is the case with SHG members and professionals, there is an increased likelihood of abuse of power, in which professionals cause harm to service-users (Burstow \& Weitz. 1988; McKnight, 1989; Penfold, 1992; Walsh, 1988). On the other hand, sharing resources and collaboration were mentioned as positive steps by professionals who want to share power with self-helpers. When professionals share power, this creates an opportunity for consumer/survivors and 
family members to experience control, to develop new skills, and to feel more competent and effective (Lord \& Hutchison, 1993).

The differences in power and control between service users and mental health professionals do not occur in a vacuum. Rather, they are embedded in larger social structures. All helping professions are organized in a hierarchical manner, in which professionals are in a dominant position relative to service-users (Illich, 1977; Reiff, 1974). Feminist analyses of the mental health system also raise awareness of power dynamics. For example, Chesler (1989) has shown how the male-dominated mental health system has contributed to the subordination of women in society. Thus, professions can be an instrument of social control used to preserve the status quo (Foucault, 1961; Gramsci, 1971).

Like Stewart et al. (1994), we found that both self-helpers and professionals wanted to move toward more positive relationships, characterized by mutual respect, support, and open communication. These are the qualities of professionals and network members that marginalized people have found to be critical in facilitating their growth and personal empowerment (Lord \& Hutchison, 1993). Self-helpers say it is very important for professionals to listen to their voices and experiences, to respect their opinions, and to support them in achieving their goals.

Moreover, both groups mentioned the need for collaboration and resourcesharing as means of reducing the power imbalance between self-helpers and professionals. While self-helpers believed relationships could move in this desired direction, they were less sanguine than professionals about the possibility of equality in the relationship. Professionals, in particular, seemed unaware that they hold a privileged economic status and power base relative to consumer/survivors. The social conditions of poverty, unemployment, poor quality housing, lack of voice and choice, and stigmatization that many consumer/survivors face (Nelson \& Walsh-Bowers, 1994) reduce the possibility of attaining truly equal partnerships with professionals. Chamberlin (1978) argues that partnerships between consumerl survivors and professionals cannot exist, and that consumer/survivor SHGs should instead adopt a separatist model. Labonté (1993) believes that partnerships are possible when all partners have established their own legitimacy and power, and that providing resources to the group with limited power is an important part of building the foundations for a partnership to occur. The Ontario Ministry of Health's Consumer/Survivor Development Initiative (CSDI) is one tangible mechanism that can be used to fund consumer-driven organizations in the mental health field (Trainor \& Tremblay, 1992).

To change professional ideology and practices, both professionals and selfhelpers said education of professionals about SHGs is the most important intervention strategy. Similarly, many writers and researchers in the self-help field have emphasized the importance of professional education and training (e.g., Borkman, 1990; Stewart et al., 1994). Incorporating material on SHGs into university courses, inviting SHG members to classes to speak about their experiences, visiting SHG meetings, offering practicum opportunities with SHGs, and providing continuing education to professionals through self-help clearinghouses are some concrete ways that people can learn about SHGs. Education about SHGs in professional training schools might serve a preventive function in reducing some of the negative aspects of relationships, like negative attitudes and use of language and labels, and 
in promoting some of the more desirable qualities for relationships, such as respect, support, and communication. However, education of professionals about SHGs can only change professional ideology and practices when it is rooted in an alternative paradigm, based on values of social justice, citizen participation, and self-determination (Prilleltensky, 1994) and the importance of a psychological sense of community (Sarason, 1974). Merely providing information to professionals about SHGs will not be sufficient to change their world views. Participants also said there is a need for ongoing interaction between professionals and selfhelpers to build positive relationships. Opportunities for interaction are needed to develop mutual understanding and trust and to use conflict, which is inevitable between two such very different groups (Labonté, 1993), to promote growth and change, Developing a sense of community can extend beyond SHGs to relationships between SHG members and professionals.

To reduce the imbalance in power and control between self-helpers and professionals, participants mentioned the need for consumer and family participation in planning and service delivery, professional encouragement of such participation, and actual decision-making power to make participation meaningful. These suggestions are congruent with those made by others who have written about consumer participation in the mental health field (Church, 1992, 1994; Church \& Reville, 1989: Valentine \& Capponi, 1989). In particular, there is a need to change mainstream organizations to reduce barriers and make them more friendly and open to consumer participation (Valentine \& Capponi, 1989). Such change will likely be uncomfortable for professionals as their very identities, roles, and assumptions will be called into question (Church, 1992, 1994). While none of the participants mentioned reallocating resources from mainstream mental health agencies to sHGs and self-help organizations, this type of fundamental change will likely be necessary to develop a strong foundation from which SHGs can grow (Labonté, 1993). In this regard, there is a need for a careful evaluation of government funding for self-help organizations, such as the CSDI initiative in Ontario (Trainor \& Tremblay, 1992).

Overall, the self-helpers and professionals who participated in this study were quite optimistic about the development of more positive and equitable relationships. However, it should be noted that the people who participated were those who were quite interested in developing better working relationships. Many of the professionals in the study were quite supportive of self-help, with one person having helped to start SHGs at both the local and provincial levels. Also, although psychiatrists and psychologists were invited to participate, none did. This is unfortunate as many of the concerns that self-helpers had about professionals pertained specifically to psychiatrists. Thus, the sample was biased toward those with a favourable attitude toward self-help and consumer participation.

In conclusion, this study has added to our understanding of the relationships between SHGs and professionals in several ways. First, our findings, like those of Stewart et al. (1994), underscore the importance of people's lived experiences, which goes beyond previous studies focussing solely on attitudes. Second, we extend previous research with the development of a grounded theory, in which professional ideology and practices and power and control are central constructs for understanding and changing the relationships between SHGs and professionals. Third, we illustrated the usefulness of a participatory action research approach, 
which has the potential for creating change, as well as for increasing understanding (Lavoie, 1984). The small sample sizes in this study limit the breadth and generalizability of the findings. What we lose in terms of generalizability, we gain in terms of depth and richness of the findings.

Future research in this area needs to investigate the process of change in mental health organizations that aspire to alter the status quo and allow for more meaningful participation of consumer/survivors and family members (Church \& Reville, 1989; Trainor \& Church, 1984; Trainor et al., 1992). Such research should focus on: (a) change at multiple levels (e.g., individual, organizational, community, social policy). (b) both process and outcome, and (c) sources of resistance and support for change (Church, 1992, 1994; Lord \& Hutchison, 1993; Nelson, 1994). Finally, a participatory action research strategy (Chesler, 1991; Lavoie, 1984) is best suited to such endeavours in the mental health field, as professional researchers, like practitioners, must change their ideology and practices and share power and control with various stakeholder groups to provide information, to promote change, and to develop theory.

\section{RÉSUMÉ}

A l'aide de méthodes qualitatives, nous avons étudié les relations actuelles et les relations soulaitées entre les membres de groupes d'entraide constitués de consommateurs et de survivants de soins pour la santé mentale ainsi que leurs parents et les professionnels de la santé mentale. Deux thèmes principaux, les pratiques et l'idéologie professionnelle ainsi que le pouvoir et le contrôle, ont permis de cerner les aspects positifs et négatifs de la relation vécue par le participant. Pour s'approcher autant que possible du type de relation souhaitée, les participants ont indiqué les besoins de formation et d'interaction continue entre les participants des groupes d'entraide et les professionnels pour que les pratiques et l'idéologie professionnelle actuelles changent; ils ont également indiqué que la participation des consommateurs et de la famille au processus décisionnel est nécessaire pour réduire le déséquilibre qui existe sur le plan du pouvoir entre les participants des groupes d'entraide et les professionnels. Dans la discussion, il est également question de la portée des résultats pour que des changements soient apportés à la formation, a la pratique, et a la recherche.

\section{REFERENCES}

Borkman, T.J. (1990). Experiential, professional, and lay frames of reference. In T.J. Powell (Ed.), Working with self-help (pp. 3-30). Silver Spring. MD: National Association of Social Workers.

Bryant, N. (1990). Self-help groups and professionals; Cooperation or conflict. In A.H. Katz \& E.I. Bender (Eds.), Helping one another: Self-help groups in a changing world (pp. 183-195), Oakland, CA: Third Party Publishing.

Burstow, B., \& Weitz, D. (1988).(Eds.), Shrink resistant: The struggle against psychiatry in Canada. Vancouver: New Star Books.

Chamberlin, J. (1978). On our onn: Patient-controlled altematives to the mental health system. New York: McGraw-Hill.

Chesler, M.A. (1990). The "dangers" of self-help groups: Understanding and challenging professionals' views. In T.J. Powell (Ed.), Working with self-help (pp. 301-324). Silver Spring, MD: National Association of Social Workers. 
Chesler. M.A. (1991). Participatory action research with self-help groups: An alteruative paradigm for inquiry and action. American Journal of Community Psychology, 19, 757 768.

Chesler, P. (1989). Women and madness. New York: Harcourt Brace Jovanovich.

Church. K. (1992). Moving over: A commentary on power-sharing. Toronto: Psychiatric Leadership Facilitation Program.

Church, K. (1994). Working together across difference, Toronto: Psychiatric Leadership Facilitation Program.

Church. K., \& Reville, D. (1989), User involvement in the mental health field in Canada. Canada's Mental Health, 37(2), 22-25.

Emerick, R.E. (1990). Self-help groups for former patients: Relations with mental health professionals. Hospital and Community Psychiatry, 41, 401-407.

Farquharson, A. (1990). Self-helpers and professionals, In J.-M. Romeder (Ed.), The selfhelp way: Mutual aid and health (pp. 113-124). Otuawa: Canadian Council on Social Development.

Foucault, M. (1961). Madners and civilization. New York: Random House,

Gottlieb, B.H. (1982). Mutual help groups: Members' views of their benefits and of roles for professionals. Prevention in Human Services, 1, 55-67.

Gramsci. A. (1971). Selections from the prison notebooks. London: Lawrence \& Wishart.

Grosser, R.C., \& Vine, P. (1991). Families as advocates for the mentally ill: A survey of characteristics and service needs. American Joumal of Orthopsychiatry, 61, 282-290.

Hanson, J.G., \& Rapp, C.A. (1992). Families' perceptions of community mental health programs for their relatives with a severe mental illness. Commusity Mental Health Joumal, 28, 181-197.

Illich, L. (1977). Disabling professions. In I. Hiich (Ed.). Disabling professions (pp, 11-40), London: Marion Boyars.

Jacobs, M., \& Goodman, G. (1989). Psychology of self-help groups: Predictions on partnership. American Psychologist, 44, 536-545.

Kazz, A.H., \& Bender, E.I. (1990). Professional self-help group relationships. In A.H. Katz \& E.1. Bender (Eds.), Helping one another: Self-help groups in a changing world (pp. 155-168). Oakland, CA: Third Party Publishing.

Labonté, R. (1993). Community development and partnerships. Canadian Joumal of Publir Health, 84, 237-240.

Lavoie, F, (1984). Action research: A new model of interaction between the professional and self-help groups. In A. Gartner \& F. Riessman (Eds.), The self thelp revolution (pp. 173182). New York: Human Sciences.

Levine, M. (1982), Method or madness: On the alienation of the professional. Joumal of Community Psychology, 10, 3-14.

Levy, L (1978), Self-help groups viewed by mental health professionals: A survey and comments. American Joumal of Commanity Psychology, 6, 305-313.

Lincoln, Y.S., \& Guba, E.G. (1985). Naturalistic inquiry. Beverly Hills: Sage.

Lord, J., \& Hutchison, P. (1993). The process of empowerment: Implications for theory and practice. Canadian Joumal of Community Mental Health, I2(1), 5-22.

Lotery, J.L., \& Jacobs, M.K. (1994). The involvement of self-help groups with mental health and medical professionals: The self-helpers' perspective, Prevention in Human Senvices, $11,279-302$.

Madara, E.J. (1990). Maximizing the potential for community self-help through clearinghouse approaches. Prevention in Human Services, 7, 109-138.

McKnight, J. (1989). Do no harm: Policy options that meet human needs. Social Policy, $20(1), 5-15$.

Nelson, G. (1994). The development of a mental health coalition: A case study. American Jountal of Community Psychology, 22, 229-255.

Nelson, G., \& Walsh-Bowers, R. (1994). Psychology and psychiatric survivors. American Psychologist, 49, 895-896. 
Peirson, L., \& Prilleltensky, I. (1994). Understanding school change to facilitate prevention: A study of change in a secondary school. Canadian Journal of Community Mental Health, 13(2), 127-143.

Penfold, P.S. (1992). Sexual abuse by therapists: Maintaining the conspiracy of silence. Canadian Joumal of Community Mental Health, II(1), 5-15.

Pomeroy, E., \& Trainor, J. (1991). Families of people with mental illness. Toronto: Canadian Mental Health Association/National.

Powell, T.J. (1990). Self-help, professional heip, and informal help: Competing or complementary systems? In T.J. Powell (Ed.), Working with self-help (pp. 31-49). Silver Spring, MD: National Association of Social Workers.

Prilleltensky, 1. (1994). Empowerment in mainstream psychology: Legitimacy, obstacles, and possibilities. Canadian Psychology, 35, 358-374.

Raiff, N.R. (1984). Some health related outcomes of self-help participation: Recovery, Inc. as a case example of a self-help organization in mental health. In A. Gartner \& F. Riessman (Eds.), The self-help revolution (pp. 183-193), New York: Human Sciences.

Rappaport, J. (1993). Narrative studies, personal stories, and identity transformation in the mutual heip context. Joumal of Applied Behavioral Science, 29, 239-256.

Reiff, R. (1974). The control of knowledge: The power of the helping professions. Joumal of Applied Behavioral Science, 10, 451-461.

Salzer, M.S., McFisdden, L., \& Rappaport, J. (in press), Professional views of self-help groups: A comparative and contextual analysis. Administration and Policy in Mental Health.

Sarason, S.B. (1974). The psychological sense of community: Prospects for a community psychology. San Francisco: Jossey-Bass.

Stewart, M., Banks, S., Crossman, D., \& Poel, D. (1994). Partnerships between health professionals and self-help groups: Meanings and mechanisms. Prevention in Human Services, 11, 199-240.

Strauss, A., \& Corbin, J. (1990). Basics of qualitative research: Grounded theory procedures and techniques. Newbury Park, CA: Sage.

Todres, R. (1982). Professional attitudes, awareness, and use of self-help groups. Prevention in Human Services, 1, 91-98.

Trainor, J., \& Church, K. (1984). A framework for support for people with severe mental disabilities. Toronto: Canadian Mental Health Association/National,

Trainor, J., Church, K., Pape, B., Pomeroy, E., Reville, D., Teff, B., Lakaski, C., \& Renaud, L. (1992). Building a framework for support: Developing a sector-based policy model for people with serious mental illness. Canada's Mental Health, 40(1), 25-29.

Trainor, J., \& Tremblay, J. (1992). Consumer/survivor businesses in Ontario: Challenging the rehabilitation model. Canadian Joumal of Community Mental Health, 1/(2), 65-77.

Tyler, F.B., Pargament, K.I., \& Gatz, M. (1983). The resource collaborator role: A model for interactions involving psychologists. American Psychologist, 38, 388-398.

Valentine, M. B., \& Capponi, P. (1989). Mental health consumer participation on boards and committees: Barriers and strategies. Canada's Mental Health, 37(2), 8-12.

Walsh, R. (1988). The dark side of our moon: The iatrogenic aspects of professional psychology. Joumal of Community Psychology, 16, 244-248. 